\title{
Closing the knowledge gaps on MERS: three and half years since its detection, what have we learnt and what needs to be done urgently?
}

\author{
Mamunur Rahman Malik ${ }^{7}$ and Jaouad Mahjour ${ }^{2}$
}

The Middle East respiratory syndrome coronavirus (MERS-Cov), first detected in 2012 (1), continues to cause health concerns owing to the grave uncertainties that have surrounded the virus since it emerged. Three and half years after the first known human infection was detected, cases continue to be reported every month, over $85 \%$ of which have been from Saudi Arabia and other countries in the Arabian Peninsula (2).

Despite its low levels of transmission, the virus presents an uncertain future as a number of critical knowledge gaps on the source and route of transmission have hindered the global response to this emerging infection.

The epidemiology of MERS-Cov has not changed over time. The majority of cases are male and the median age is 49 years. About 35\% of reported cases have been fatal, mostly in those with underlying chronic medical conditions. The epidemiological patterns of the disease seen so far in the countries of the Arabian Peninsula suggest repeated sporadic introduction of the causative virus into human populations from an animal source with limited human-tohuman transmission (2). Unlike SARS, community transmission is rare (3). However, secondary transmissions have primarily occurred in health-care settings, often resulting in small to large nosocomial hospital outbreaks. At least four generations of transmissions were noted in a recent hospital outbreak in Riyadh, Saudi Arabia (4). Similar multiple transmission chains also occurred in Jordan, and in South Korea during May-July 2015 (5).

MERS-Cov is a zoonotic virus and the evidence suggests that human infections are associated with exposure to animals, especially camels (6). Either direct or indirect contact with dromedary camels could be the primary risk factors for human infections that are acquired in the community (7). We now know that MERS-Cov is widespread in camel populations in the Arabian Peninsula and some African countries such as Egypt, Ethiopia, Kenya, Nigeria, Sudan, and Tunisia (8). However, these findings do not explain whether the virus was circulating in the dromedaries of these countries before the first human infection was detected in 2012.

From the public health perspective, the risk factors for nosocomial outbreaks are overcrowding, lack of proper assessment and triaging of suspected patients, uncontrolled patient movement, absence of patient cohorting and poor compliance with infection control practices by health-care workers $(4,9)$. Evidence has also shown that early recognition of suspected case, appropriate triaging and isolation of suspected patient and rapid implementation of appropriate infection control measures were linked to interruption of transmission in hospitals (10).

Like any other emerging infection, MERS-Cov has the potential to cause an explosive outbreak with rapid dispersion of the virus into susceptible populations. Such an example can be drawn from the recent experience with the Ebola Virus Disease (EVD) and also from the last hospital outbreak in South Korea. For almost 38 years, EVD was restricted to localized outbreaks in a few remote regions of Central Africa that were rapidly brought under control (11), until the latest outbreak in western Africa which spiralled into a global health emergency. Likewise, no secondary spread of MERS-CoV from any index patient had been reported from any of the 26 countries where the virus was introduced through a returning traveller (5). However, cases during the South Korean outbreak of MERS were associated with secondary, tertiary, quaternary and even quinary transmission following an index patient returning from a country on the Arabian Peninsula (5). This hospital outbreak of MERS, the biggest case-cluster of the virus outside the Peninsula, is a stark reminder that MERS-Cov is an international health threat, particularly in situations with weak or fragile health systems, and poor surveillance and detection capacity. Furthermore, as with all coronaviruses, MERS-Cov is prone to mutation and may acquire an enhanced ability to become more easily transmissible $(10,12)$. If this happens, the likelihood of yet another major global health emergency cannot be ruled out.

A substantial amount of research on MERS-Cov has been carried out since 
its discovery. However, a number of knowledge gaps still remain and filling these is critical both to advancing our understanding of MERS-Cov infection and, more importantly, to improving the effectiveness of the global response to the virus. First, the zoonotic sources of infection should continue to be investigated with a focus on identifying possible zoonotic hosts and environmental sources of the virus that may play a role in transmission between camels and humans. Second, further serological surveys, contact tracing and other surveillance need to be conducted urgently in the affected countries to quantify asymptomatic or mild infections and their possible role in community transmission, and to identify exposure risk factors for non-human sources of infection. Additionally, targeted research to understand the pathogenesis, viral kinetics, duration of viral shedding and period of infectiousness of this virus in camels and humans and protective immune response for human infection is important in order to interrupt virus transmission from animals to humans. For the animal health sector, it is essential to monitor the seasonal pattern of virus circulation in camels through active and laboratory-based targeted surveillance. Knowledge on seasonality will be useful for limiting human infections.

WHO has been leading and coordinating the global efforts to minimize the threats of MERS-CoV. To accelerate progress in resolving these knowledge gaps, WHO has so far organized four international scientific meetings bringing together international scientists working on MERS-CoV and public health officials from the affected countries. The public health research agenda has been endorsed in these meetings but progress in conducting studies has been slow. Considering the current uncertainties surrounding the virus and its presumed capability to cause a global health emergency, such research is a vital and urgent priority. Without this research and the information it will provide, our ability to respond effectively to the virus remains uncertain.

The global fight against the virus will only be a decisive success if a sustained global response is launched; $\mathrm{WHO}$ is committed to working with all stakeholders to achieve this.

\section{References}

1. Zaki AM, van Boheemen S, Bestebroer TM, Osterhaus AD, Fouchier RA. Isolation of a novel coronavirus from a man with pneumonia in Saudi Arabia. N Engl J Med. 2012 Nov 8;367(19):1814-20. PMID:23075143

2. Ben Embarek PK, Van Kerkhove MD. Middle East respiratory syndrome coronavirus (MERS-CoV): current situation 3 years after the virus was first identified. Wkly Epidemiol Rec. 2015 May 15;90(20):245-50. PMID:25980038

3. Banik GR, Khandaker G, Rashid H. Middle East respiratory syndrome coronavirus "MERS-CoV": current knowledge gaps. Paediatr Respir Rev. 2015 Jun;16(3):197-202. PMID:26002405

4. Balkhy $\mathrm{HH}$, Alenazi TH, Alshamrani MM, Baffoe-Bonnie H, AlAbdely HM, El-Saed A, et al. Notes from the Field: Nosocomial Outbreak of Middle East Respiratory Syndrome in a Large Tertiary Care Hospital - Riyadh, Saudi Arabia, 2015. MMWR Morb Mortal Wkly Rep. 2016 Feb 19;65(6):163-4. PMID:26890816

5. Petersen E, Hui DS, Perlman S, Zumla A. Middle East Respiratory Syndrome - advancing the public health and research agenda on MERS - lessons from the South Korea outbreak. Int J Infect Dis. 2015 Jul;36:54-5. 10.1016/j.ijid.2015.06.004. PMID:26072036

6. Haagmans BL, Al Dhahiry SH, Reusken CB, Raj VS, Galiano M, Myers R, et al. Middle East respiratory syndrome coronavirus in dromedary camels: an outbreak investigation. Lancet Infect Dis. 2014 Feb;14(2):140-5. PMID:24355866

7. Alraddadi BM, Watson JT, Almarashi A, Abedi GR, Turkistani A, Sadran M, et al. Risk Factors for Primary Middle East Respiratory Syndrome Coronavirus Illness in Humans, Saudi Arabia, 2014. Emerg Infect Dis. 2016 Jan;22(1):49-55. PMID:26692185

8. Müller MA, Corman VM, Jores J, Meyer B, Younan M, Liljander A, et al. MERS coronavirus neutralizing antibodies in camels, Eastern Africa, 1983-1997. Emerg Infect Dis. 2014 Dec;20(12):2093-5. PMID:25425139

9. Oboho IK, Tomczyk SM, Al-Asmari AM, Banjar AA, Al-Mugti H, Aloraini MS, et al. 2014 MERS-CoV outbreak in Jeddah-a link to health care facilities. N Engl J Med. 2015 Feb 26;372(9):846-54. PMID:25714162

10. Hui DS, Perlman S, Zumla A. Spread of MERS to South Korea and China. Lancet Respir Med. 2015 Jul;3(7):509-10. PMID:26050550

11. Zumla A, Perlman S, McNabb SJ, Shaikh A, Heymann DL, McCloskey B, et al. Middle East respiratory syndrome in the shadow of Ebola. Lancet Respir Med. 2015 Feb;3(2):100-2. PMID:25592990

12. Zumla A, Hui DS, Perlman S. Middle East respiratory syndrome. Lancet. 2015 Sep 5;386(9997):995-1007. PMID:26049252 